\title{
New hibernation systems for corrosion protection of internal substrate surfaces of chemical processing plants
}

\author{
E. Lyublinski, ${ }^{1 *}$ Y. Vaks, ${ }^{1}$ W. Rohland, ${ }^{1}$ T. Natale, ${ }^{1}$ S. Woessner, ${ }^{1}$ \\ R. Singh, ${ }^{2}$ E. Tanabe ${ }^{2}$ and M. Schultz ${ }^{3}$
}

${ }^{1}$ Northern Technologies International Corporation, 23205 Mercantile Rd., Beachwood, OH 44122, USA.*E-mail: elyublinski@,ntic.com

${ }^{2}$ Zerust, 255, São Bernardo Do Campo Avenue, Sorocaba 18085, São Paulo, Brazil

${ }^{3}$ Petrobras, República do Chile Av., Nr. 65, Rio de Janeiro - RJ, CEP: 20031-912, Brazil

\begin{abstract}
Corrosion protection of large equipment's internal surfaces (distillation towers, pipelines, tanks, boilers, heat exchangers, etc.) during storage, transportation/shipping and long term mothballing (up to 10 years) is a worldwide problem. In many cases, well-known technology for replacement of the environment with nitrogen gases cannot be applied and are not always efficient enough. In addition to their limited protection ability, these approaches tend to be cumbersome, complicated, labor intensive, very expensive and create safety issues. This paper describes a system that reduces the environment corrosiveness by decreasing the relative humidity (RH) to a level that allows achieving corrosion protection of different metals in any sealed enclosures. In addition this new system delivers the volatile corrosion inhibitors (VCI) into enclosures that increases the corrosion protection efficiency and decreases the corrosion if the enclosures have some leakage. This system creates the required RH and concentration of VCI very fast. It is compact equipment and can be moved for applying corrosion protection in different locations. In the paper, we will present a mobile system that can be periodically used for many kinds of equipment in different facilities. A real system, designed, manufactured and applied for corrosion protection of mothballing equipment in one refinery will be presented and discussed.
\end{abstract}

Key words: environment, corrosion, protection, inhibitor, dehumidification, equipment, enclosures, mothballing, storage, transportation.

Received: May 1, 2015.

doi: 10.17675/2305-6894-2015-4-3-197-209 


\section{Introduction}

Corrosion of mothballed equipment is a problem in many industries worldwide, including petroleum, chemical, mining, automotive, transportation, military, etc. During maintenance, many large and expensive equipment (pipelines, boilers, tanks, reservoirs, heat exchangers, etc.) are taken out of operation for mothballing. The equipment is stored outdoors or indoor and must be protected from corrosion. The storage time can vary widely, from days up to several years [1-19].

In today's business environment, a company needs to be able to react quickly to the dynamic environment in which they exist. This means that plants/processes/equipment needs to be taken in and out of service on a routine basis. This equipment must be at any unpredictable time being ready to take back in operation. This provides a need for corrosion protection for metallic items during storage and/or transportation in different environments. This includes such items as:

- Interior of large enclosed spaces such as tanks, vessels, boilers, or piping, especially for voids and/or recessed areas of interior cavities;

- Metal parts and equipment inside any enclosed space;

- Internal surfaces of process equipment such as turbines, engines, compressors, etc.;

- Mission critical parts and assemblies that need to be stored and put quickly back into service.

In most cases the corrosion condition of internal surface of enclosures is unknown. The part of equipment can be made from different metals, including steel, copper and aluminum alloys.

Typical corrosion protection solutions for mothballed equipment include: pressurized nitrogen, rust preventive (RP) oils, removal of existing environment by vacuuming or dehumidification and applying inhibitors. There are often problems associated with these methods, including:

- The cost of maintaining a positive pressure nitrogen system and safety issues (nitrogen can leak from the enclosed space if not properly sealed);

- RP oils are line of sight/direct contact, no protection is provided for recessed/difficult to access areas; and

- Desiccant needs to be frequently replaced/replenished. Saturated desiccant with temperature fluctuations can increase corrosion. Desiccant must be removed before putting the asset back into service.

This paper presents a summary of new corrosion protection technologies which are based on a new principal and/or a combination of the traditional technologies resulting in improved corrosion protection at a lower overall cost. The presented technologies can greatly reduce corrosion for a wide variety of types and sizes of equipment (Figure 1). 

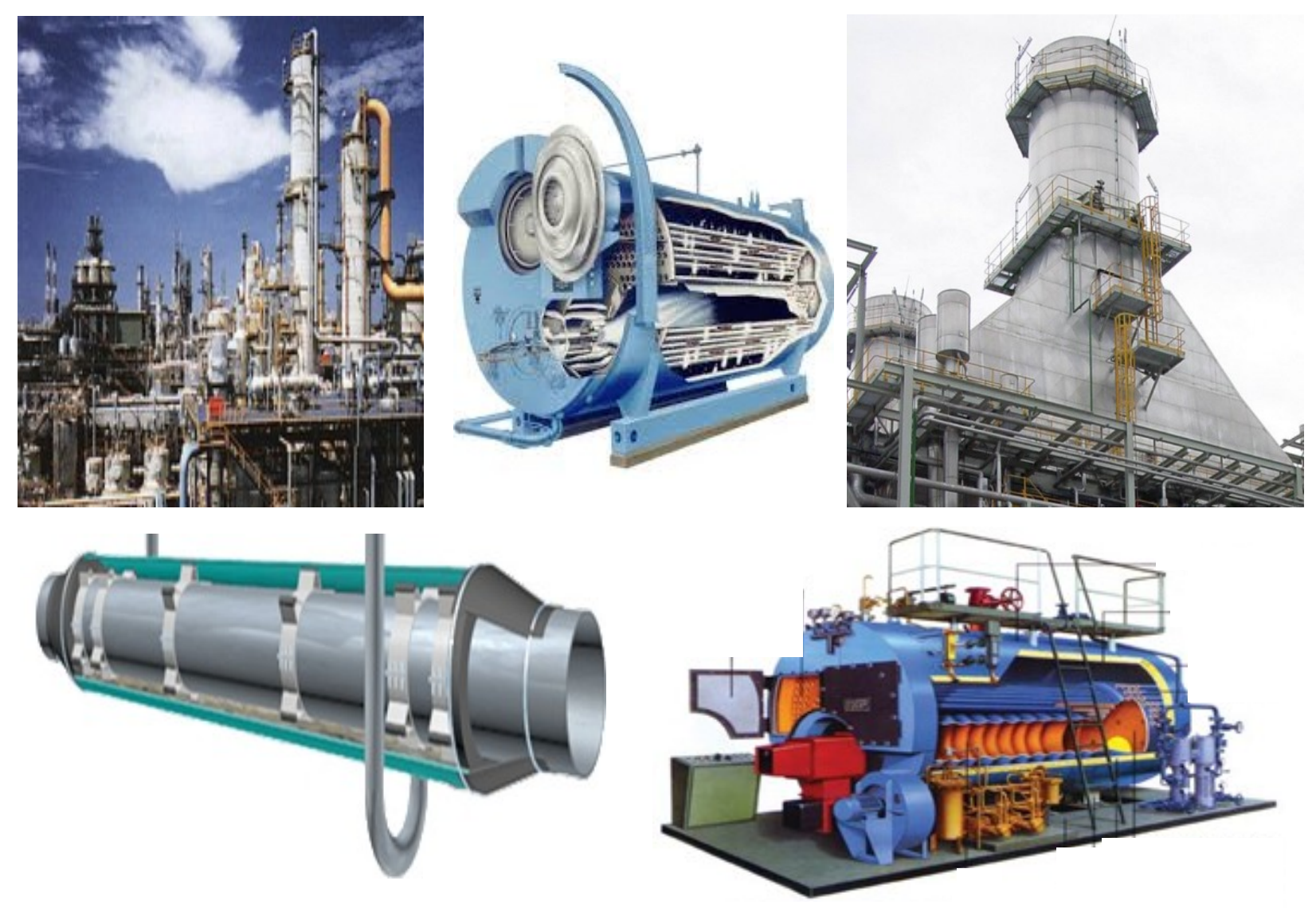

Figure 1. Examples of equipment taken out of operation for mothballing.

During storage, protection is needed for both external and internal surfaces of the equipment. The exterior surfaces of the equipment are typically protected by traditional methods like coatings. The internal surfaces are often bare or minimally protected and sometimes have difficult to access areas [3, 4, 10, 15].

Corrosion rates on these internal surfaces depend on the design of the equipment, materials, atmospheric/gaseous conditions, relative humidity $(\mathrm{RH})$, presence of aqueous solutions, temperature and the frequency of temperature changes, corrosion condition of the internal surfaces, etc.

Below some general information is presented (Table 1) that shows the problems with corrosion in the enclosures of mothaballing equipment. In all cases the corrosion exists for all maim metals and the alloys presented in enclosures. These are only the general examples of corrosion rate taken into consideration that only $30 \%$ during the mothballing time the fluctuation of the temperature create condensation of the water vapors. 
Table 1. Examples of corrosion rate of main metals in a wide range of environment in enclosures of mothaballing equipment.

\begin{tabular}{|c|c|c|c|c|c|c|c|c|}
\hline \multicolumn{5}{|c|}{ Corrosion environment* } & \multirow{2}{*}{ Metal } & \multicolumn{3}{|c|}{ Corrosion Rate, $\mathbf{m m} / \mathbf{y r}$ (up to): } \\
\hline \multicolumn{2}{|c|}{$\begin{array}{c}\text { Concentration } \\
\text { of gases }\left(\boldsymbol{\mu g} / \mathbf{m}^{3}\right)\end{array}$} & RH & pH & $T,{ }^{\circ} \mathrm{C}$ & & Average & Pitting & Crevice \\
\hline $\mathrm{Cl}^{-}$ & $0.3-30$ & \multirow{4}{*}{$50-100$} & \multirow{4}{*}{$3-8$} & \multirow{4}{*}{-40 to +50} & $\mathrm{Fe}$ & 0.5 & 1.0 & 1.5 \\
\hline $\mathrm{SO}_{2}$ & $0.04-2.0$ & & & & $\mathrm{Cu}$ & 0.1 & 0.05 & 0.5 \\
\hline \multirow{2}{*}{$\mathrm{H}_{2} \mathrm{~S}$} & \multirow{2}{*}{$0.07-0.2$} & & & & $\mathrm{Al}$ & 0.05 & 3.0 & 4.0 \\
\hline & & & & & $\mathrm{Zn}$ & 0.2 & 1.5 & 2.0 \\
\hline
\end{tabular}

In the environment that contain acidic compounds $\left(\mathrm{SO}_{2}, \mathrm{H}_{2} \mathrm{~S}, \mathrm{Cl}^{-}\right)$, depending on temperature, relative humidity and frequency of changing the temperature (that results in condensation) the corrosion rate can dramatically changed during mothaballing of equipment. When the temperature decreases the water vapors condensed on the surface and absorbed gaseous compounds that creates highly corrosive environment. Typical examples of corrosion rates in the mothaballing enclosure are shown in Figure 2.

These data combine all types and forms of corrosion (general, pitting and crevice) that can happen at the same times on the same surface on the part of equipment situated inside of the enclosure during mothballing. According to this data it is obvious that the corrosion problems can be solved by decreasing the $\mathrm{RH}$ in side of the enclosures near $50 \%$. But in many cases the size of equipment, environment and mothballing conditions, type of used metal parts unpredictable and during the mothaballing the applied $\mathrm{RH}$ (below 50\%) in some part of enclosures the condensation can exist and create corrosion problems.

To exclude this situation were created two types of corrosion protection systems that combine dehumidification (DH) of environment applying VCI in cases of presence of vapor condensed layers in some parts of the equipment due to fluctuation the temperature. In most cases the selected inhibitor composition that in vapor space works as VCI when absorbed in condensed water layer or in aqueous solution became SCI. In this case application of the system became very simple.

Principally two types of DH/VCI Systems (DVS-1 and DVS-2) were developed to control the corrosion in the vapor space and in solution (water or aqueous solution condensed or sedimented in the bottom of the enclosures). 




Figure 2. Corrosion rate of carbon steel in industrial environment.

DVS-1 is a packaging system (Figure 3) to control external and internal corrosion in the vapor space and in the condensed on the metal surface water or aqueous solutions. This is a two layer system that allows controlling RH inside of the first layer (VCI or plain film) and excluding the entry of moisture into the inner layer from outside through the external barrier packaging film. This system recommended in most cases for corrosion protection of external surface of any size of equipment and internal surface for not very large and complicated equipment.

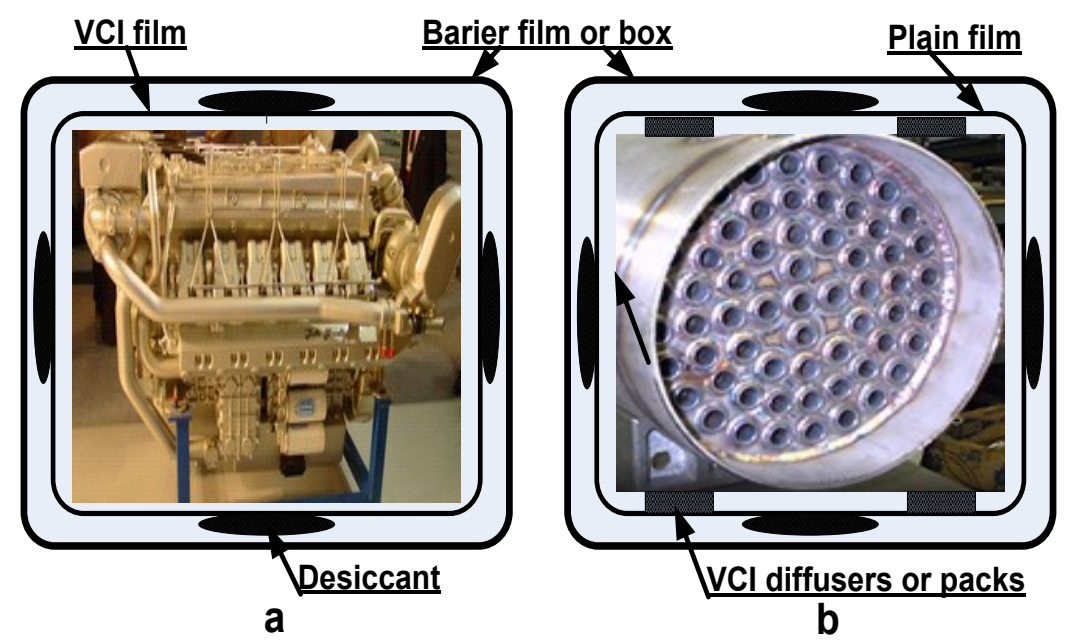

Figure 3. DVS-1 systems for corrosion protection of external and internal surfaces of mothaballing, storage or transportation of equipments. 
This system has been applied in many cases where existing packaging systems not efficient. The storage and shipment environment was extremely aggressive: $\mathrm{RH}$ of up to $100 \%$, temperature from $+40^{\circ} \mathrm{C}$ to $-20^{\circ} \mathrm{C}$, sea atmosphere, and industrial environment. For most of this equipment, only DVS-1 system is efficient and cost effective. The photos clearly show the high quality of the metal parts and equipment opened after arriving at the customer's plant (Figure 4).


Figure 4. Quality of equipments after shipping.

These results were achieved due to the differences of RH ambient and in the bags. For example, during the storage and/or shipping of equipment and metal parts at ambient temperature of +40 to $-10^{\circ} \mathrm{C}$ and $\mathrm{RH} 50-100 \%$ the following levels of $\mathrm{RH}(\%)$ were measured:

\begin{tabular}{|c|c|c|}
\hline \multirow{2}{*}{ In single VCI bag } & \multicolumn{2}{|c|}{ In DVS-1 } \\
\cline { 2 - 3 } & Inner layer & Between the layers \\
\hline $40-80$ & $20-40$ & $10-30$ \\
\hline
\end{tabular}

The many years of application experience received in the most aggressive environments, for example during the shipments through the ocean from India and UK to different countries (Figure 4), allowed the areas of DVS-1 system application to be expanded. Examples of this system application during this year for corrosion protection of large and complicated equipments are presented in Figure 5.

Taking into consideration that the condition of the internal surface of heat exchangers is unpredictable, the internal surface of each pipe was cleaned (the corrosion product removed) before applying the DVS-1 system. This will allow the VCI to reach and cover all surface areas of the pipes in the heat exchangers. This system is efficient during indoor and outdoor storage. In cases of damages this system can be easily fixed. 

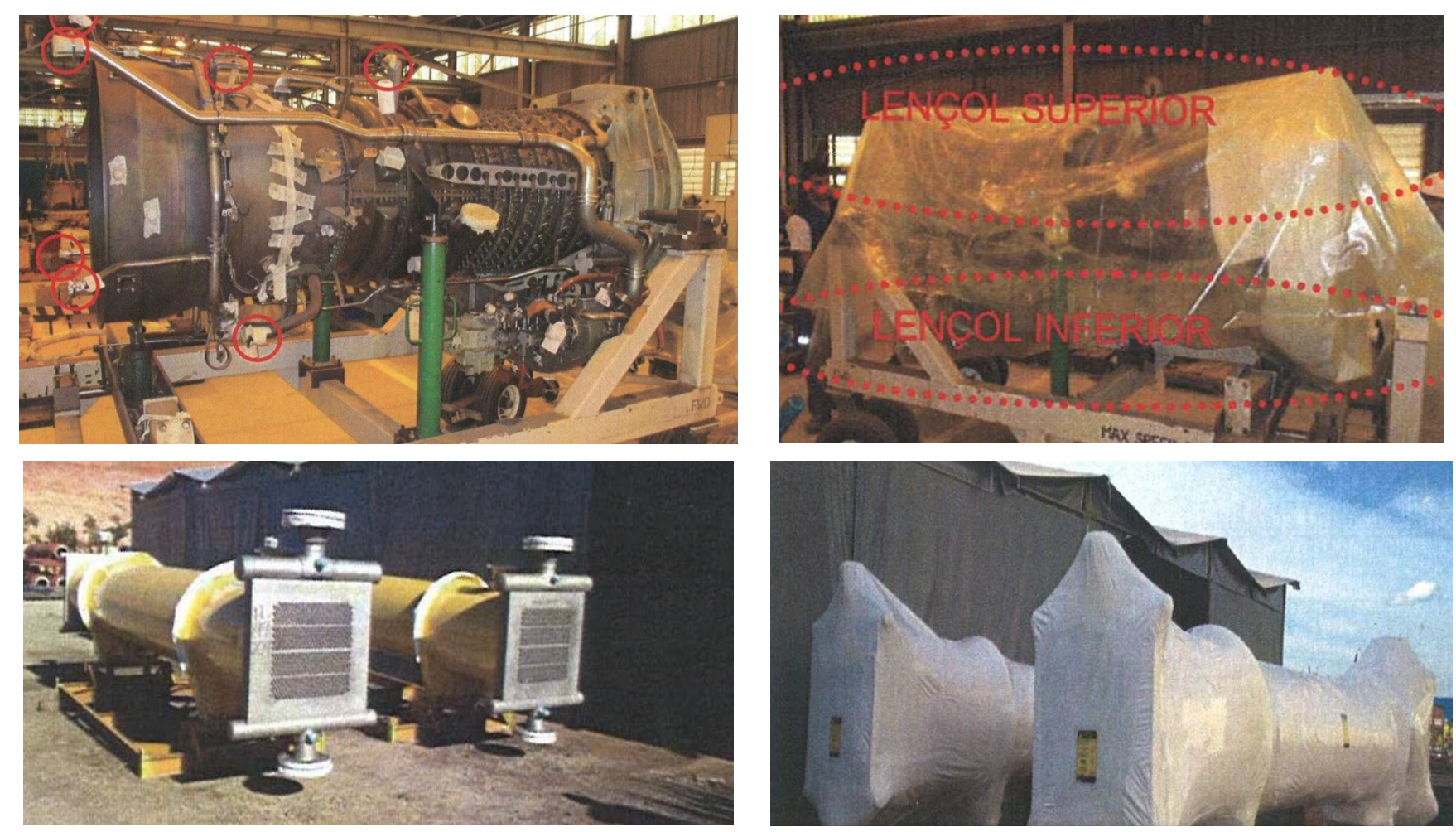

Figure 5. DVS(a) system applied for corrosion protection of large heat exchangers.

DVS-2 System is developed for corrosion protection of different type of large and complicated design of mothaballing equipment. The main advantages and disadvantages of different methods are described in Table 2.

Table 2. The advantages and disadvantages of the existing methods for corrosion protection of large enclosures.

\section{Protection method}

1. Replacement of existing environment with nitrogen $\left(\mathbf{N}_{2}\right)$

\section{Advantages}

1. $100 \%$ efficiency in case if it is possible to achieve the fully sealing of enclosure

\section{Disadvantages}

It is impossible to check that the environment was not fully replaced

Not efficient in spaces where exist liquid that cannot be replaced with nitrogen condensed

For not fully sealed enclosure the consumption of $\mathrm{N}_{2}$ is unpredictable and corrosion protection cannot be guarantied

Cost of the delivery system and $\mathbf{N}_{\mathbf{2}}$ is high

2. Applying VCI 1. Average efficiency for about $80 \%$

1. Efficiency decreases if the concentration decrease near than the protection concentration

2. Applicable in different

2. Type of inhibitor depends on environment condition and type of metals

3. Does not exist the application technology for large and complicated equipment 


\section{Protection method Advantages Disadvantages}

\begin{tabular}{|c|c|c|}
\hline 3. Dehumidification & $\begin{array}{l}\text { High efficient and } \\
\text { low cost }\end{array}$ & in fully sealed enclosures \\
\hline \multirow{6}{*}{$\begin{array}{l}\text { 4. Dehumidification + } \\
\text { VCI (DVS-2 System) }\end{array}$} & \multirow{3}{*}{$\begin{array}{l}\text { 1. This is only a system: } \\
\text { - for corrosion protection of large and } \\
\text { complicated equipment; }\end{array}$} & 1. High efficient only in fully \\
\hline & & sealed enclosures \\
\hline & & 2. The delivery system in most \\
\hline & \multirow{3}{*}{$\begin{array}{l}\text { - high efficient in unpredictable } \\
\text { environment conditions; } \\
\text { - corrosion protection begins very fast; } \\
\text { - the delivery system can be mobile and } \\
\text { used for different enclosures in different } \\
\text { places }\end{array}$} & $\begin{array}{l}\text { cases economical (less } \\
\text { expensive) in compare with }\end{array}$ \\
\hline & & \\
\hline & & $\begin{array}{l}\text { - many small enclosures if the } \\
\text { required mothaballing time is } \\
\text { large. }\end{array}$ \\
\hline
\end{tabular}

The first DH/VCI System for industrial application was designed, manufactured and tested during last year (Figure 6).

This system consists of:

- A closed system for dehumidification and/or delivery of VCI on external and internal surfaces.

- A "pump" that periodically performs dehumidification and then delivers VCI.

This is the only/unique system that allows achieving corrosion protection of complicated and very large enclosures that can contain parts from different metals. To achieve the corrosion protection of any mothballing equipment it is not necessary to know the type of metals used in the enclosures, configuration, size and condition of the metal surfaces. To achieve corrosion protection, this system includes two steps:

First step include dehumidification that allow achieving the required RH less than $50 \%$ (this is the criteria of achieving corrosion protection in vapor space). In most cases the applied RH is close to $30 \%$ ).

Second step include heating of powder of liquid VCI compounds to increase their vapor pressure and delivery VCI by using the dehumidification part of the system.

The temperature range in the system allows very fast to achieve the required vapor pressure for different VCI compounds. In some cases can be used compounds that only by heating became VCI. This is the additional advantage of this system. 


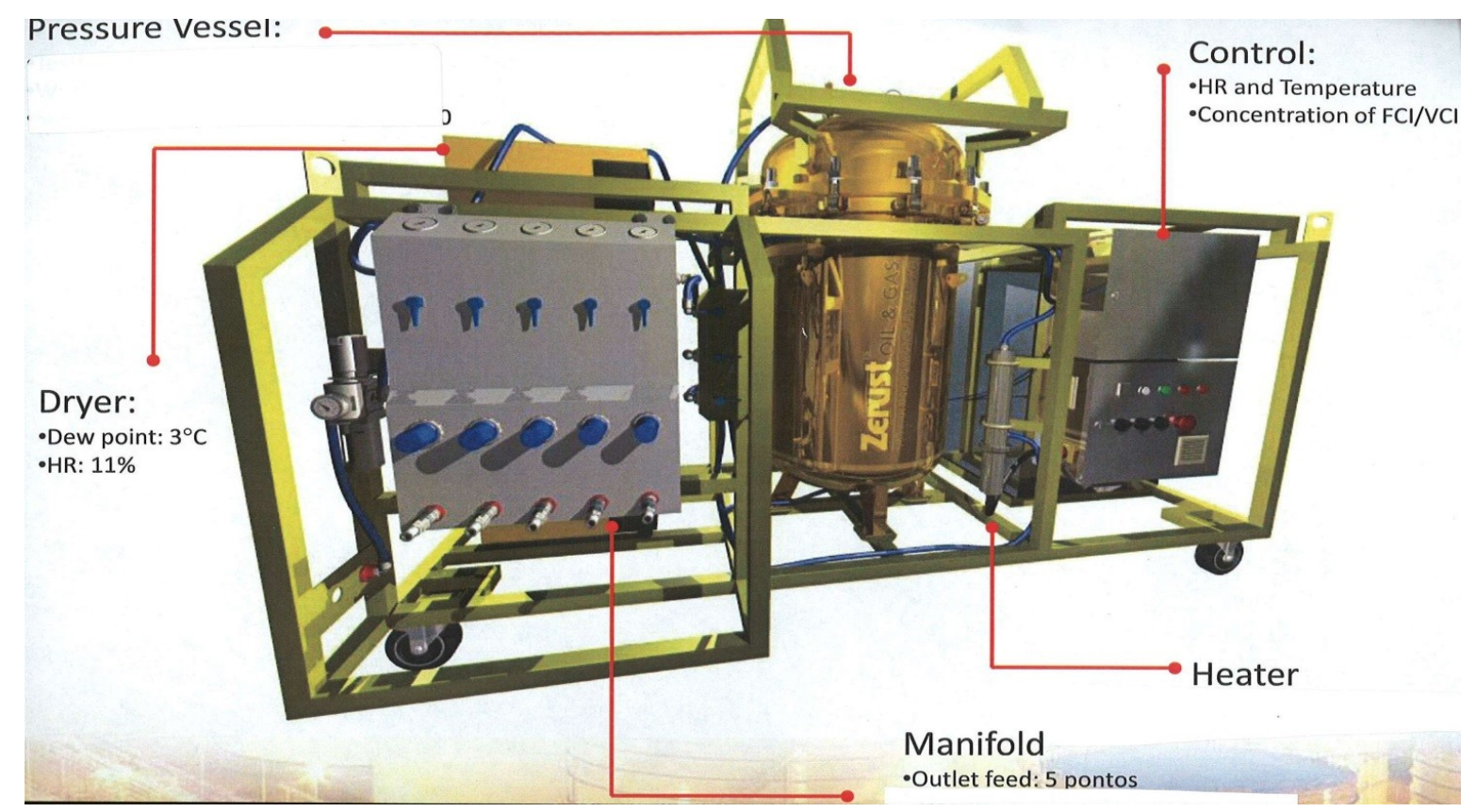

Figure 6. DVS-2 system for corrosion protection of large and complicated enclosures of equipment.
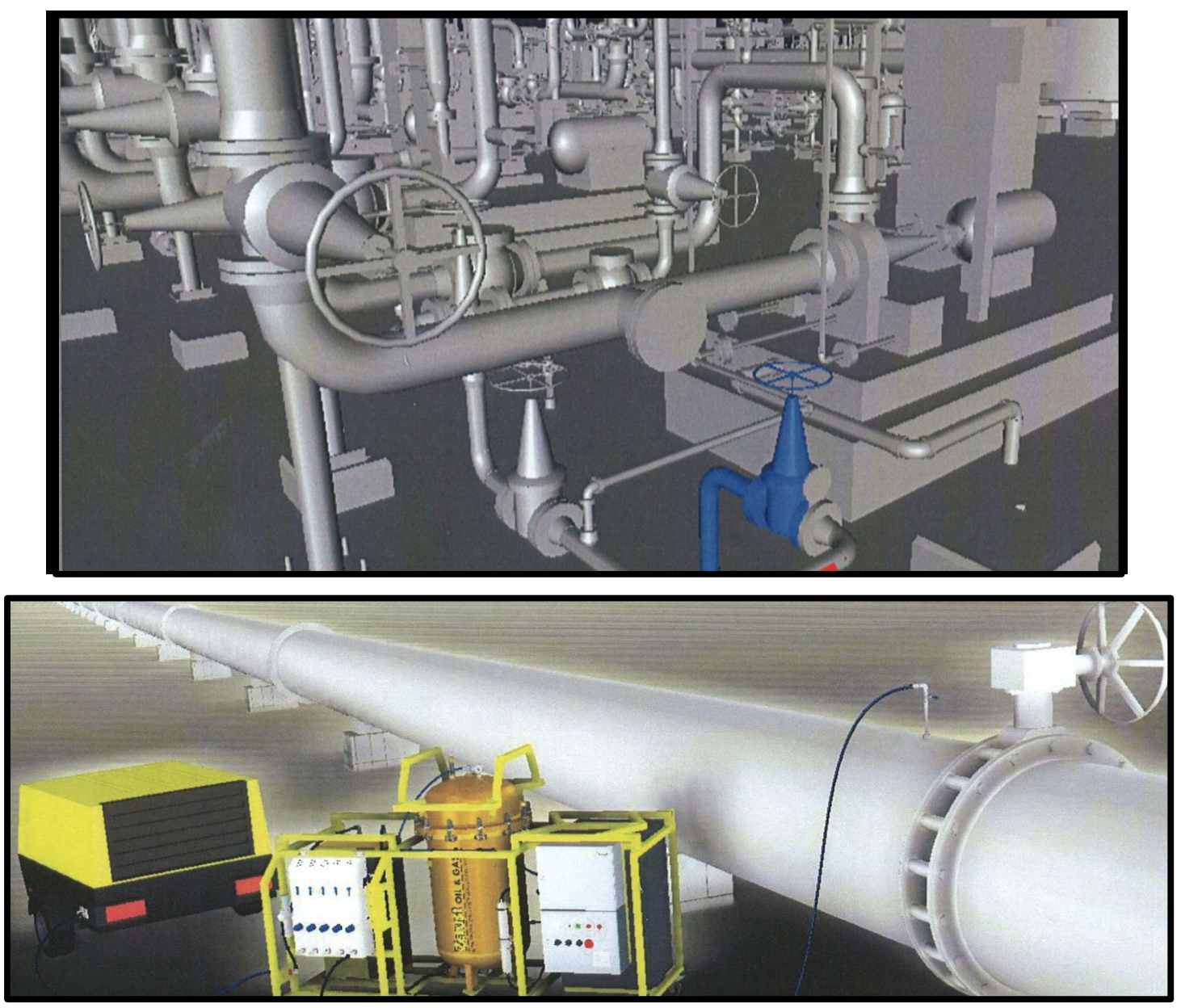

Figure 7. Mothaballing pipeline systems for applying DH-VCI (DVS-2) system. 
This first designed and manufactured equipment of the system (Figure 6) have five ports for DH and delivery of VCI and can be applied on five mothaballing equipment at the same time. In many cases it is enough to have one DH/VCI equipment to provide mothaballing much industrial enclosures in different places, for example in refineries, storage facilities and offshore platforms. This system developed for corrosion protection of very complicated equipment in some refineries. Below (Figure 7) examples of the equipment where this equipment recommended for application.

Another area for the application of the DH/VCI system is for the corrosion protection of boilers, cooling towers, heat exchangers (Figures 8,9). Proper maintenance and corrosion protection may significantly extend the service life of these equipments. Boilers and heat exchangers are somewhat unique as a protective oxide layer, magnetite, is formed on the internal surfaces of the boiler. The magnetite layer does not tend to form a continuous layer and the voids/defects in the layer are anodic to the magnetite, resulting in pitting and/or crevice corrosion. Stress cracking can sometimes occur as magnetite is a very brittle material. A DH/VCI system can offer a cost effective alternative to pressurized nitrogen.

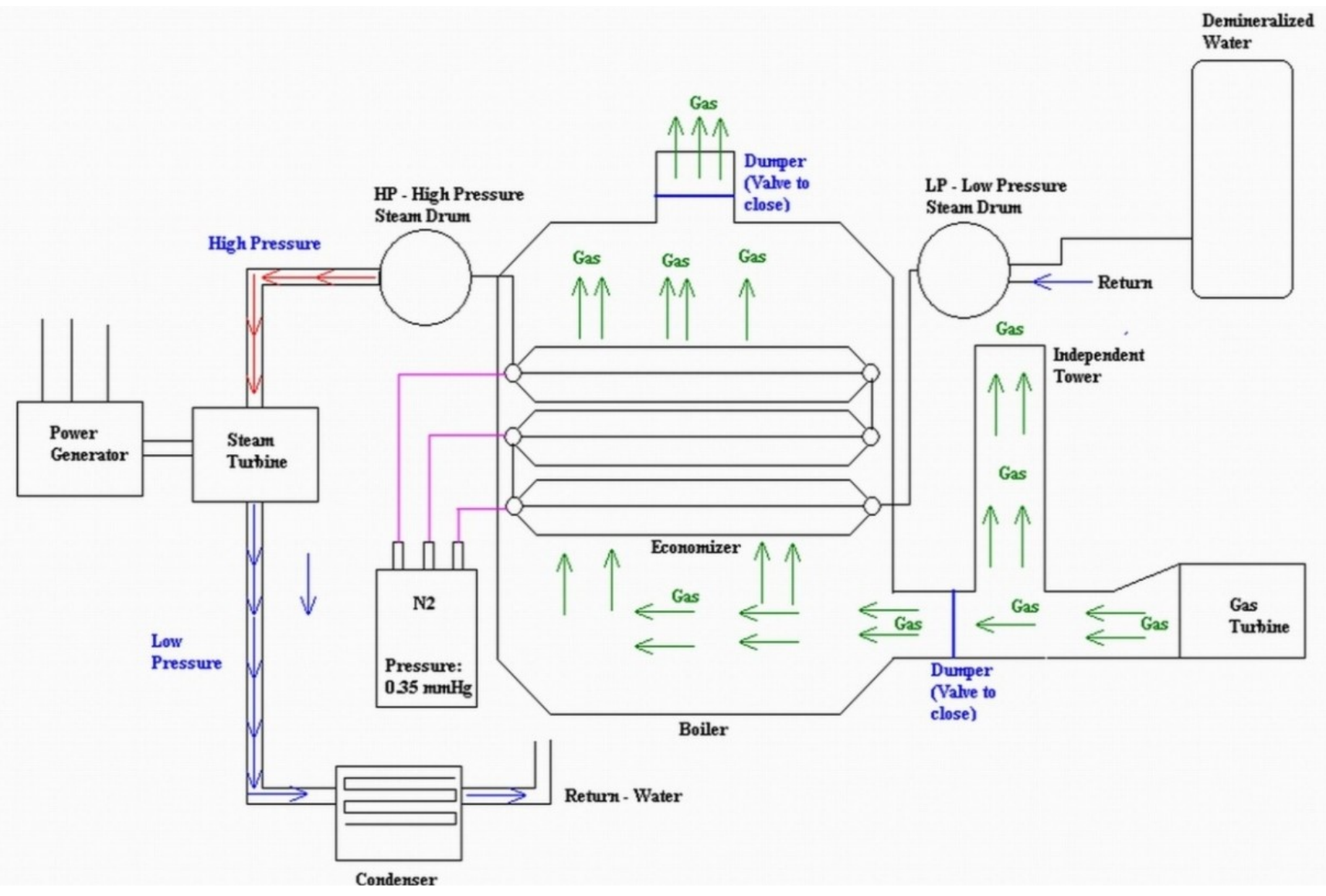

Figure 8. Principal schematics of a boiler. 



a

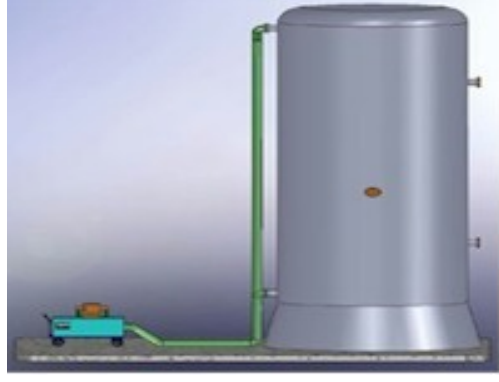

b

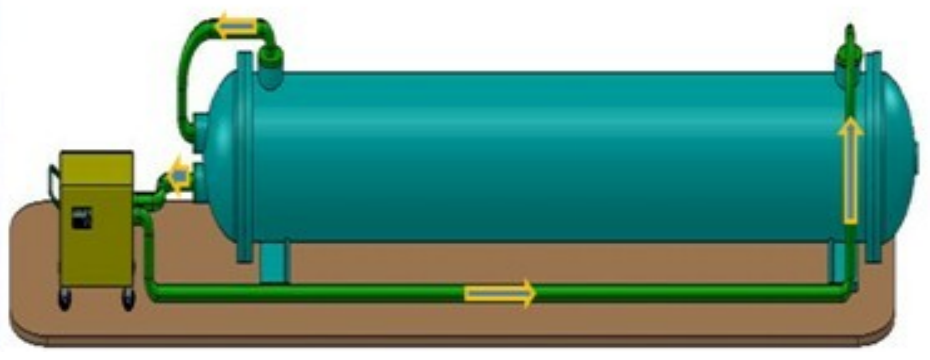

C

Figure 9. Examples of DH/VCI systems for corrosion protection of boilers $(a)$, cooling towers $(b)$, and heat exchangers $(c)$.

This system has the following advantages:

1. high efficiency and low cost;

2. the dehumidification stage decreases the corrosiveness of the environment and the required VCI concentration needed for efficient corrosion protection;

3 . VCI reduces the $\mathrm{RH}$ requirement level and ultimately the frequency of dehumidification.

The overall cost of the combined system is less than either system used alone. The system set-up time will depend on the complexity and volume of the protected equipment, but can generally be completed in several hours. The frequency of the dehumidification cycle will depend on the corrosion protection requirements. The VCI dispenser will work continuously and the frequency of VCI replacement in the dispenser will depend on the equipment volume and type of inhibitor. 


\section{Conclusions}

1. New DH/VCI systems can provide an effective means of corrosion protection for metallic items during indoor and outdoor storage, transportation and mothaballing of different type and size of equipment in different environments and application conditions, including:

- exterior and interior surface areas of equipments by using new packaging system for indoor and outdoor storage and/or transportation;

- interior of large enclosed spaces such boilers, vessels, heat exchangers, storage tanks and cisterns, cooling towers, pipes, pipelines, etc.;

- metal parts and equipment inside any enclosed space;

- internal surfaces of process equipment such as turbines, engines, compressors, etc.;

- mission critical parts and assemblies that need to be stored and put quickly back into service in all industries.

2. The new systems offer the following advantages:

- high efficiency for different metal parts and conditions;

- required service life of corrosion protection during Mothaballing in unpredictable environment conditions;

- lower cost;

- lower risk of environmental contamination.

\section{References}

1. A. Groysman, Mater. Perform., 2005, September, 44.

2. Y. I. Kuznetsov, Organic Inhibitors of Corrosion of Metals, Premium Press, New York, 1996.

3. E. Y. Lyublinski and D. A. Kubik, Combined Corrosion Protection Methods Including Inhibitors, Review on Corrosion Inhibitor Science and Technology, V. 3, NACE International, Houston, USA, 2004.

4. E. Y. Lyublinski, Y. L. Vaks, R. Singh, S. Narasivani and A. Teylor, Two Layer System for Long Term Corrosion Protection in Unpredictable Environments, EUROCORR 2009.

5. P. E. Myers, Aboveground Storage Tanks, McGraw-Hill, New York, 2000, pp. 89-138.

6. R. W. Revie, Ulig's Corrosion Handbook, John Wiley \& Sons, New York, 2000, pp. 108, 521 and 529.

7. P. R. Roberge, Handbook of Corrosion Engineering, McGraw-Hill, New York, 1999, p. 833.

8. I. L. Rozenfel'd, Ingibitory korrozii (Corrosion Inhibitors), Moscow, Khimiya, 1977 (in Russian). 
9. V. S. Sastri, Corrosion Inhibitors. Principles and Applications, John Wiley \& Sons, New York, 1998.

10. R. J. Twigg, Guidelines for the Mothballing of Process Plants, Materials Technology Institute of the Chemical Process Industries, Inc., MTI Publication No. 34, ${ }^{\text {rd }}$ printing, 2002.

11. W. J. Gonzalez, Implementing the Proper Lay-Up Procedures for Industrial Boilers and Their Auxiliaries, Watertech '95, Houston, TX, November, 1994.

12. H. H. Ulig and R. W. Revie, Corrosion and Corrosion Control, Wiley Interscience, Third Edition, 1985, Chapter 9.

13. R. J. Twigg, Guidelines for the Mothballing of Process Plants, National Association of Corrosion Engineers, 1989.

14. Annual Chem/Petrochem and Refinery Shutdowns and Turnarounds Conference, 2013, Dallas, USA.

15. E. Lyublinski, Y. Vaks, T. Natale, M. Posner, W. Rohland, S. Woessner, R. Singh and H. Souza Siriaco, Corrosion Protection of Mothballed Equipment, NACE-2014, USA, Paper 4335.

16. N. N. Andreev and Yu. I. Kuznetsov, Int. J. Corros. Scale Inhib., 2012, 1, no. 2, 146. doi: 10.17675/2305-6894-2012-1-2-146-153

17. N. N. Andreev and Yu. I. Kuznetsov, Int. J. Corros. Scale Inhib., 2013, 2, no. 1, 39. doi: 10.17675/2305-6894-2013-2-1-039-052

18. A. I. Altsybeeva, V. V. Burlov, N. S. Fedorova and T. M. Kuzinova, Int. J. Corros. Scale Inhib., 2013, 2, no. 3, 194. doi: 10.17675/2305-6894-2013-2-3-194-202

19. L. E. Tsygankova, M. N. Esina, V. I. Vigdorovich and N. V. Shel, Int. J. Corros. Scale Inhib., 2014, 3, no. 1, 48. doi: 10.17675/2305-6894-2014-3-1-048-058 